\title{
Electronic market research and the impact of consumerization: An interview with Hubert Österle
}

\author{
Rainer Alt, Leipzig University, rainer.alt@uni-leipzig.de
}

Published in: Electronic Markets 24(2014)4, pp. 251-253. DOI 10.1007/s12525-014-0175-5

\section{Background information on Hubert Österle}

Since 1980 Hubert Österle, born 1949 in Austria, has been a professor of information management at the University of St. Gallen, Switzerland. He was one of the few who successfully shaped the landscape of "Wirtschaftsinformatik", or the domain of business information systems, not only in academia, but also in practice. This thinking began with being a consultant at IBM Germany after his Ph.D. at the University of Nürnberg, Germany. He then decided to join academia again and completed his postdoctoral work (habilitation) on the "Design of information systems" at the Technical University of Dortmund in 1980. After that, he became full professor at the University of St. Gallen and in 1989, he not only founded the Institute of Information Management, but also the Information Management Group (IMG), a company which before being acquired by S\&T Group in 2007 comprised 600 employees worldwide. In 1997, he initiated the executive MBA program "business engineering" at the University of St. Gallen and in 2003, the Business Engineering Institute St. Gallen (BEI). Hubert Österle has been a member of the editorial board of numerous journals and in 2007, he was elected to continue the work of Beat Schmid, who was the first Editor-in-Chief of Electronic Markets. This is Hubert's last issue as editor-in-chief of Electronic Markets and he agreed to share some of his thoughts on the area of networked business and electronic markets in the following interview. His interest for electronic business emerged from the area of process management and integrated information systems, which he researched primarily following the consortial research method. Inspired by the organization of research at the Massachussetts Institute of Technology (MIT) in 1988, he was successful in motivating companies to share their challenges with regard to IT and to jointly search for practical solutions with researchers. 
Numerous of these projects - so-called competence centers-were finished during his 34 years in St.

Gallen. On May 14, 2014, Hubert held his farewell speech as Professor at the University of St. Gallen.

\section{The interview}

Held on September 10, 2014

Rainer Alt (RA): When did you start your work in the field of information technology?

Hubert Österle (HOE): The very beginning was a course in FORTRAN programming in 1967. As students we could get a very basic impression of the huge potential of IT. I was fascinated.

RA: How did this fascination develop in the 47 years of technical developments after your first contact with IT?

HOE: First of all: IT with its permanent innovation keeps you young or at least busy and flexible. If you want to understand the opportunities of IT for people and business, you have to keep up with the development day after day. If we look behind great innovations like search engines, the internet of things, or augmented reality, there seems to be a basic attitude to succeed in making use of the technological advances. Take a specific new concept of IT usage as for example self-driving cars, neglect the present restrictions of technology, and imagine a digital service for businesses or the daily life of consumers, based on the underlying theoretical IS and IT concepts. A few years later technology will be able to realize the new solution.

RA: Can you give examples?

HOE: This was true with data base management systems, personal computers, mobile computers, the internet, and ERP systems. You can see this especially in the area of electronic markets. The theoretical concept was convincing from the very beginning i.e. in the second half of the 1980s. It was a very long journey with a lot of disappointments, but today you see and use this kind of coordination everywhere: Airbnb, eBay and market places for mobile apps are even part of the daily life of consumers. In the near future, it will be the case with easy access to all kind of automatically collected data, with sensors and actuators everywhere, and with the transformation of search engines into recommendation machines. 
We are going to explore new kinds of collaboration in our societies. One big challenge will be: How will the consumer use the millions of digital services from apps, from the Internet, and from smart devices? Will the likes of Google, Facebook, and Tencent integrate all the personal services in superapps for all needs of people? Will they manage our life, as Eric Schmidt—at that time CEO of Googledeclared as Google's vision in 2011 ?

RA: What are the consumer services you specifically see in the "super-app"?

HOE: If you consider the current state of digital service usage you can identify some dominant functionalities: People consume content from the web, from daily news to BLOGs and, for example, health information. People communicate via phone, email, video, instant messages and the like. People organize themselves in virtual communities or, for example, massively multiplayer online games. People use IT to coordinate their private and business life. That means they arrange appointments, use contact databases, declare their taxes, manage their finances etc. If we look at the potential integration of all this information and services we can envision some aspects of a future consumer super-app, the consumer's digital assistant. This app or its precursors will not only change the life of consumers, but also the business models of enterprises.

RA: Does that mean big monopolies?

HOE: Yes, at least oligopolies. Or call it dominant ecosystems. It is hard to envisage small, new ecosystems besides Microsoft, Apple, Google, Facebook, Amazon, Tencent, and Alibaba. They accumulate consumer data, apps, app developers, patents, contracts with partners, and last but not least, enormous financial resources. Only break-through innovations as these companies had themselves in the beginning can change the game. The odds are in favor of monopolies. For the businesses that means a gamechanging sales channel as the booking services for the hotel industry. For the consumer that means the choice between a handful of dominant players.

RA: Is that necessarily a bad message for the consumers or are monopolies the drivers of innovation as Peter Thiel, the first external investor of Facebook, notes in his book together with Blake Masters?

HOE: The analysis of the innovation power of monopolies by Thiel and Masters is correct during the time span of building up the monopoly. There, innovation and value for the customer are the drivers of 
the business. It has to be fundamentally questioned as soon as we talk about well-established monopolies, as we are familiar from railways, postal services, telecommunication companies and the like.

RA: Your research dominantly focused on Business Engineering. In recent years you postulated a need for Life Engineering. What do you mean by that?

HOE: In our economies money is the basic criterion for most decisions. Financial success decides if an investment proposal is accepted, decides if a manager stays in his position, if a product survives, or a company remains independent. Therefore, companies develop and provide services and products, which produce a high EBIT margin and contribute to the enterprise value. Consumers are free to choose the products and services with the best value for their quality of life. The question is if these valuable products and services are on the market and if the consumer is able to recognize and select them. Is the drug recommended by a pharmaceutical company the best cure for a specific disease? Is the retirement arrangement provided by a bank or insurance company to the best of the consumer? Is an energy drink beneficial to one's health? Does an exclusive brand really enhance the sustainable quality of life or the indebtedness of the consumer? What does really increase the happiness of people in the long term? Enterprises are built by humans to profit from the division of labor. Nowadays we could get the impression that people exist for the benefit of enterprises instead of enterprises for the benefit of people. With the huge potential of future IT applications we probably should start to better understand happiness or quality of life and develop guidelines for consumers and enterprises. Could that be a new field of IS research? The concept of a consumer ERP, that means a private administration system, designed from the position of the consumer, could be a challenge for IS research. Or just the aspect of ownership of personal data, by the consumer or by big consumer portals. If we believe in the arrival of singularity in the sense of Ray Kurzweil, life engineering is an urgent discipline. It would define the rules for digital assistants managing our future lives.

RA: What, based on your experience, are the biggest challenges for academic research?

HOE: Where do you think you will learn more about innovative concepts of IT, about business potentials, about IT impact on society and economy? Will it be in the top ranked scientific journals of 
IS research or in books like "Zero to One" (Thiel and Masters 2014), in "The New Digital Age: Reshaping the Future of People, Nations and Business" (Schmidt and Cohen 2013), in "How to Create a Mind: The Secret of Human Thought Revealed" (Kurzweil 2013), or in "The SecondMachine Age:Work, Progress, and Prosperity in a Time of Brilliant Technologies" (Brynjolfsson and McAfee 2014)? Is publication of papers for the mainstream journals and conferences the best use of our skills? Or should our talented young researchers better work on innovative solutions for a better world? Where do you expect more valuable contributions to our future? Of course, this is also a challenge for EM (Electronic Markets - The International Journal on Networked Business). When I took over the responsibility as an editor-in-chief from Beat Schmid almost 10 years ago I had a big goal: Make EM a journal of relevance that gives young researchers an opportunity for their academic career and at the same time is read and used by practitioners who want to understand the digital age, in particular the potentials of electronic markets and other forms of business networking. In 2014, I have to state that this goal was a little heroic. Academia moved and still moves in the direction of irrelevance. It is hard to write papers with practical relevance, it is very hard to find reviewers for that kind of papers, and it is even harder to create the necessary reputation in a self-preserving scientific community. On the other hand, methodological rigidity and practical impact of the results in the sense of design-oriented research seem to be a strong argument for an academic career. It will be interesting to watch if EM or other journals succeed in strengthening the relevance of their publications. I ponder over this assessment of academic IS research if it is simply the attitude of an old man looking back to better times or if it is in fact a serious danger for our discipline.

RA: This year, you retired after 34 years as a professor from the University of St. Gallen. What are you going to do with your new freedom?

HOE: I had a great time with great people at a great university and a great journal over a very long time. Especially I would like to thank all who have contributed to the academic success of EM, the authors, the reviewers, the editorial board, and last but not least the executive team. Now I am very glad that my career was in a time when we were accepted as researchers with a high interest in real life and relevant topics. Innovation and conceptualization had a higher esteem by our community than rigor and statistical methods. So now I will not just have time for my hobbies, mountaineering and hiking, skiing and soccer, 
but also to follow the development of IT and the progress in consumer services. And I have the privilege to still be part of a research team. Our goal is to use IT to enable independent living for senior citizens, but also for single parents, for families with two working parents, and other people with a need to simplify their daily life. The core is a double-sided market for personal services. We try to realize one of the dreams of the early years of electronic markets with the technology available now and in the near future.

RA: Hubert, thank you for the interview.

\section{References}

Brynjolfsson, E., \& McAfee, A. (2014). The second machine age: Work, progress, and prosperity in a time of brilliant technologies. New York: Norton \& Company.

Kurzweil, R. (2013). How to create a mind: The secret of human thought revealed. New York: Penguin.

Schmidt, E., \& Cohen, J. (2013). The new digital age: Reshaping the future of people, nations and business. New York: Knopf.

Thiel, P., \& Masters, B. (2014) Zero to one. New York: Crown Business. 